than make out a degree of aimilarity which will sanction the use of a common term. The practice of grouping cases and distinguishing particular combinations of symptoms by terms more or less intelligently applied, is, of course, necessary, but we must never lose sight of the fact that calling a series of phenomena "hysterical" does not make it 80. I am not thinking of gross errors of diagnosis, but of cases well worked out, still not on that account identical. When, therefore, we speak of a " protean malady," it is needful to bear in mind that we are fully as likely to be making out the quality of proteanism, by a Frankenstein process, as recognising varieties of the same so-called disease. The caution to which I would pointis indispensable in dealing with hysteria in all its manifestations, or, as I prefer to say, the varied physical and mental disturbances commonly associated under the term "hysterical." In a medical sense, therefore, we must, I think, reject the postulate which Dr. Coupland offers when he says, "Clearly so protean a malady (as hysteria) can have no simple etiological foundation." Meanwhile, I am quite prepared to admit that " it is but a confession of ignorance on our part to refer it invariably to a single source." I was not aware that physicians did refer hysteria "invariably to a single source," but perhaps that is a proof of $\mathrm{my}$ ignorance; so pray let it pass.

We know little or nothing of hysteria; and $I$ venture to think our information is scarcely likely to improve while symptoms are raised to the level of diseases, and contingent phenomenal disorders are treated as primary affections-for example, so long as physicians report cases of "catalepsy," as though the cataleptic condition could be pathognomonic. In nineteen out of twenty cases of what is roughly called "mental disease" the cause is physical, and the mind symptoms are reflexly induced. Nevertheless I think patbologists fail in ignoring the purely mental phase of morbid action; and, while they are not slow to recognise the physical causes of mind symptoms, they are too prone to overlook the possibility of direct mental causation of disordered states and disturbances which seem wholly physical. This may sound like an old story, but it needs to be recited in a new form.

Dr. Henry Thompson, as I understand the controversy, recognises the presence of mental forces as elements in the production of the state called hysteria. Dr. Althaus discards the hypothesis of their operation when he can exclude the presumption that patients intentionally or consciously deceive themselves or others. In fact, he does not conceive it possible that mental forces should act without the cognisance of the subject. Dr. Broadbent would seem to be open to conviction, but finds himself face to face with a difficulty he cannot surmount. Mr. Brudenell Carter would be in the same predicament, but, being a bolder man, he takes the obstacle at a flying leap. His solution of the problem may be paraphrased thus: "What you cannot understand do not believe; set the mystery down to the imagination of the patient, or his wilful and ingenious imposture." This is a facile mode of reasoning, but it is not scientific. In short, Mr. Brudenell Carter's hypothesis of deception had no place in the argument. If the "facts" were fictions, no more needed to be said on the subject, except perhaps to point out the stupidity of the observers duped. I must leave Mr. Brudenell Carter to settle the imputation with those upon whom it was cast. Dr. Glover was amply justified in asserting " that the time had come for a more careful investigation into the various forms of anæsthesia." $\mathrm{H}_{\theta}$ might have added ischæmia and many other mysterious phenomena to the list.

We want a better word to use in the place of " mystery." The unknown is not necessarily unknowable; it may simply mean unexplored. I venture to think what so grievously puzzled the disputants at the Clinical Society the other night falls under this description. It is curious to observe the manner in which extremes meet in a dis. cussion carried on without guiding lines of reasoning. Not a few of the views broached on this occasion were worthy of the earlier centuries in the history of medicine. The alchemists would have gloried in the mystic laudation of gold. It seems to have been forgotten that so simple a factor as the difference of specific gravity in coins used in the Salpétrière experiments may have produced widely diverse physical effects on the surface nerve-organs, and whether by a piece of gold or a brass garter kept in appo. sition with the skin, the terminal filaments might be stimulated, mechanically-as titillation, or the gentle pressure of a substance so soft as the hand, will sometimes relieve severe pain and induce sleep. The great point forgotten, however, was the undoubted connexion which sub. sists between mind and body, and the strange way they react upon each other, even during the state known as unconscious cerebration.

Almost anyone who likes to try the experiment honestly will find that he can by practice obtain such control over his sensations as to extinguish the sense of pain. The old flagellists and self-torturers of the ecstatic sects did not so much overcome the sense of suffer ing as destroy it by establishing a condition of anæsthesia by mental effort. The proof of this can be made by direct personal experiment, and what is capable of being done by way of inquiry is daily accomplished in morbid conditions of the brain. The experience of medical superintendents of asylums will bear mo out in asserting that, under the influence of disordered mental states-for example, delusionsindividuals of highly sensitive temperament will endure what should be agony, while the fact that the anæsthesia in only temporary is found in the fact that in dressing the wounds self-inflicted, or almost preternaturally borne by these patients, they suffer acute pain. I am not drawing on my imagination for these facts. I distinctly affirm that the etatement is truthful. Again, as regards the ischrmia, wounds do not always bleed when the attention is powerfully diverted, as in the case of injuries received under intense excitement in battle. The hæmorrhage not unfrequently commences after the excitement is over. I differ from Dr. Coupland as to the production of such a phenomenon as blushing or pallor. I am convinced by extensive observation and experiment that not only the heart but the arterioles may be brought under the control of the will. It is even possible to cure the condition of hypersensitive vascularity, which causes blushing on the slightest provocation, by the roundabout process of making the act voluntary, and thus bringing it under control. In the same way some inveterate cases of chorea have been cured by converting involuntary acts into a subjective result of volition, and, so to say, bridging over the chasm between impulse and will. Some forms of stammering may be successfully treated in this way. The victims of the involuntary muscular contraction or spasm which breaks the rbythm of the voluntary act intentionally produces the jactatory phenomenon, and thus obtains the mastery. I am not speaking of cases in which the impossibility of maintaining a continuous muscular contraction is the result of weakness, when increased effort may cover, and, in process of time, cure the defect.

To sum up, I believe " hysteria " to be a misleading term for conditions very different in their nature, and springing from totally distinct and dissimilar causes. When the name is discarded we shall find the artificial group of morbid phenomena fall apart to the great advantage of science. Investigation is what we now need, and I renture to urge that the scope of the inquiry must include what seem to be purely mental states. It is one of the regrettable consequences of making a specialty of "mental disease," in which the mind symptoms of physical disease are arbitrarily filched from medicine to compose a mock science of " psychological medicine," that this great and important subject cannot be adequately studied. If all that is available in the way of evidence could be brought to bear upon it in a single focus the mystery could probably be dispelled. I am, Sir, yours, \&c.,

Scientific Club, Savile-row

$$
\text { J. Mortimer GRanviLite, M.D. }
$$

\section{UNIVERSITY OF LONDON.}

PROPOSED EXTRAORDINART MEETING OF CONVOCATION.

$$
\text { To the Editor of THE LANCET. }
$$

SIR, - In justice to those who have signed the requisition about to be placed in the hands of the chairman of Convocation, you will, I hope, allow me to offer a few words of explanation.

At the meeting of Convocation on May 9th, 1876, a resolution was passed, without division, that a special committee should be appointed "for the purpose of considering what changes in the constitution of the University are de- 
sirable." Subsequently, however, when the mover of the resolution, Mr. Hensm $₫$, nominated the committee, objection was made to the absence of graduates in medicine from the list, and the actual appointment of the committee was postponed till "the meeting of Convocation appointed to be held on the 20th June." At this meeting the election was, through other causes, again deferred. The resolution of May 9th not having been rescinded, Mr. Hensman. again brought the matter before the House at the meeting in January of the present year. Then, however, it was strongly urged that it would be inexpedient to appoint a committee with what was styled "a roving commission," and without a definite programme of reform. This argument apparently prevailed with the House. The suggestion was also made that the Annual Committee would take up the constitutional question. Further action in the matter was therefore deferred till after the meeting held in last May. But in the report presented to that meeting the Annual Commitsee gave no indication either of having already taken the question into consideration or of being about to do so. On the 4th of July the Senate resolved "that it is desirable that a new charter should be obtained "for the purpose of granting degrees to women in Arts, Laws, and Science. This fact, together with the powerful agitation on the part of $O$ wens College, showed that the question of reform ought not to be allowed any longer to rest. In compliance, therefore, with the wish expressed at the meeting in Junury, the scheme of reform, which is now before the Univergity, was arranged. As soon after the vacation as was pructicable the Clerk of Convocation was consulted as to the business likely to come before the House at the inext ordinary meeting. From the information thus obtained the conclusion was drawn that there was no reasonable probability that the resolution on constitutional reform could be tak in into consideration at all at the January meeting. Uuder these circumstances, and the preliminary consideration of the questions at issue being amply sufficient to occupy the whole of the time during which a House can usually be kept together, steps were at once taken towards obtaiking an extraor dinary meeting.

In view of these facts I fail to see how the conduct of the requisitionists can be fairly spoken of as "injudicious." Neither do I see how the Senate can be hampered thereby, since they have affirmed, by a large majority, the desirable. ness of obtaining a new charter. What I have said may be sufficient to show also that the action of the requisitionists is not fairly attributable to a desire to "shelve the Annual Committee." In fact, so far as I am personally concerned, I may say that the appointment of the special committee appears to me a matter of subordinate consequence. What is of chief importance is, that the proposed changes should befully considered by the members of the University and the public.

I am, Sir, your obedient servant,

London, Nor. 6th, 1877 . Thomas Truer, M.A.

\section{THE}

\section{MEDICAL ASPECTS OF TOTAL ABSTINENCE.} To the Editor of THE LANCET.

SiR,-In reading the letter from Mr. Brudenell Carter on the subject of Alcoholic Abstention, it occurred to me that my own experience, though diametrically opposed to that of the writer, still, in a marked manner, went to support his argument, "In medio," \&c. I have all my life been what is called an "abstainer," simply from utter distaste for all forms of alcoholic stimulants. In stating this, I do not mean that I never touch alcohol. On the contrary, I believe it to be a very valuable medicine, and as such use it. When I feel "done up," or have a headache, to which I am somewhat subject, I find a glass of wine very useful. I never take it, however, without being rendered drowsy and disinclined for exertion. A short time since, I had rather a sudden pressure of work, and was thoroughly " out of sorts," with relaxed sore-throat, headache, and general debility. A medical friend prescribed for me, telling me at the same time that he was sure I was wrong in not taking aome form of alcobol as a regular thing. I felt so seedy that $I$ was half inclined to give credit to his reasoning, and determined to make a fair trial. By his advice I took a couple of glasses of wine and a glass of beer daily. I cer tainly felt better for it at first, but was always drowsy after each dose. I continued this plan for a week or so, when was one night suddenly seized with vomiting and diarrhoea. As there was no other apparent cause for this attack I attributed it to the alcohol, and discontinued its use. Since then I have returned to my cup of tea or coffee and my glass of water. I have no drowsiness, and am able to do a full day's, and sometimes a night's work, without any fatigue.

My own experience has led me to look upon alcohol as a medicine rather than as a food. At all events it is not an article of diet necessary for me. I believe, however, that a great deal depends upon the habits formed in early life. As a child I was never offered, or, indeed, allowed to touch, either beer or wines, except as medicine. The consequence was that I acquired a distaste for all forms of alcohol, and this has lasted me for thirty years, and will, I believe, last me for the remainder of my life. I am, however, fully persuaded that when the habit has been acquired the necessity has also been established. And so long as the indulgence of the habit is kept within the actual bounds of the neces. sity, no harm will be done. It is, however, when these bounds are passed that the harmful áction of alcohol begins. In this case, as in all others, the harm lies in the excess. With regard to confirmed drunkards, the only possible chance of cure lies in total abstinence. A dipsomaniac, however, cannot be brought to this point gradually. It must be adopted in full at once. No doubt there would be a certain amount of systematic disturbance caused by the sudden removal of the alcohol, which has been the main article of diet, but by a careful substitution of nutritious substances in sufficient quantity, this difficulty may be easily overcome, and the patient, from being, if not legally insane, actually so, will become a useful member of society, so long as he adheres to total abstinence from alcohol, - total, be cause, having once yielded fully to the temptation, he is in danger of relapsing, if he takes one step in the old road. It is, therefore, apparent that if any authoritative fiat is to go forth with regard to the use of alcohol, it must be one that avoids the "Scylla" pointed out by Mr. Brudenell Carter's experience, and the "Charybdis" of my own. Medio tutissimus ire - Yours truly,

Holloway, Oct. 29th, 1877.

W. Henry Kesteven.

\section{To the Editor of THW LANCET.}

SIr,-Mr. Biudenell Carter, in your impression of the 27th of Ostoher, concludes his letter with the expression of a hope that he may "obtain from others, records of their experience" on the dietetic use of alcohol.

Let me commence by stating, as he does, that I am a very small eater, and have been for many years a very hard brainworker, and that my time is so engaged that for some years I have not had one holiday.

It was my habit to take daily, at dinner, a glass of Bass's ale or of Guinness's porter, or sometimes of "good old wine," and in the evening, before I retired to bed, I took often, not always, a glass of Irish whisky toddy, or of brandy and water. My friends told me that one who worked hard required a stimulant, and so I took it, being under the impression that it really did me good. True, I often suffered from feelings like indigestion, had a furred tongue often; after dinner, dared not read nor write, as headache and a flushed face resulted. In the morning my mouth was often thick and dry, and an iuclination to sick stomach prevailed. My fare being of the simplest character, these symptoms were not easily accounted for.

At length, about fifteen months ago, I was speaking to a habitual drunkard about the diggrace and ruin he was bringing on himself. "Do you not take anything?" said he, with an arch smile. "W Wy, yes," I replied, "just a little; but"-I saw his smile growing broader-" but, from this moment, I shall give it up as long as you do." The bargain was struck. We shook hands. My friend remained a total abstainer for a fortnight. I have not tasted since. My obligation ceased when my friend began to drink, but I felt so much better, my digestion so much stronger, my mouth not thick and dry, my stomach not sick, the tendency to headache gone, that I concluded alcohol was my enemy, and alcohol since I have carefully avoided. 